\title{
Anacleto. El tiempo y el don en una ruta del transporte público (Tijuana, México)
}

Anacleto: Time and the Gift on a Public Transit Route (Tijuana, Mexico)

RESUMEN

En Tijuana, en la frontera México-Estados Unidos, desvencijados camiones conectan la periferia urbana con una de las garitas terrestres más transitadas del mundo. Estas rutas conforman los estratos más bajos del sistema de movilidad fronteriza; en ellas, el imperativo de la movilidad capitalista -convertida por la frontera en un valor supremo- lleva la explotación laboral a un extremo y fragiliza la solidaridad entre los trabajadores. Entre ellos, emerge un impulso hacia el "don puro": el don absolutamente desinteresado, que apenas puede reconocerse como tal. Este impulso toma forma en el contraste entre diferentes tipos de tiempo; se manifiesta de manera importante en los actos de comunicación lingüística, que convierte en dones delicados y fugaces. Centrándose en la (no) relación entre la antropóloga y su interlocutor principal, este ensayo usa las complejidades éticas del intercambio etnográfico como punto de partida para explorar la relación entre el tiempo, el don y la comunicación en la frontera.

Palabras clave: movilidad, tiempo, intercambio, comunicación, frontera, México.
RIHAN YEH

Doctora en Antropología.

Profesora en el Departamento

de Antropología de la

Universidad de California

San Diego, California,

Estados Unidos.

口 ryeh@ucsd.edu

(1) ORCID: 0000-0003-1818-8059

soogle Scholar 


\begin{abstract}
In Tijuana, at Mexico's border with the United States, worn-out old buses connect the urban periphery with one of the busiest ports of entry in the world. These routes make up the lowest strata of the border's system of mobility; in them, the imperative of capitalist mobility, which the border turns into a supreme value, takes exploitation to an extreme and makes fragile any incipient solidarity between workers. Amongst them, an impulse towards the "pure gift" emerges: the absolutely disinterested gift that can barely be recognized as such. This impulse takes shape in the contrast between different kinds of time; it manifests itself, importantly, in acts of linguistic communication, which appear as delicate and fleeting gifts. Focusing on the (non)relationship between the anthropologist and her main interlocutor, this essay uses the ethical complexities of the ethnographic exchange as a starting point for exploring the relationship between time, the gift and communication at the border.
\end{abstract}

Keywords: mobility, time, exchange, communication, border, Mexico.

nacleto es nombre propio que no es nombre propio; puede ser
una alusión al más "tontito y dejado" - como me lo explicó una
amiga- de Las Ardillitas de Lalo Guerrero, pero se puede usar también de manera similar a fulano, para referirse a alguien sin nombrarlo. Como pseudónimo es, así, perfecto, algo como ponerse Pseudónimo: el nombre de no tener nombre. Empiezo con esta pequeña aporía, que mi "informante clave" de los últimos años colocó entre nosotros, pues, me parece, condensa y exacerba las aporías que le dieron forma a todo nuestro efímero intercambio etnográfico ${ }^{1}$.

$$
* * *
$$

Conocí a Anacleto en 2014. Había regresado a Tijuana con el firme propósito de emprender un nuevo proyecto de investigación, y aunque no sabía muy bien sobre qué, había pistas que apuntaban hacia el tránsito vial; por otra parte, el mundo del transporte público en Tijuana me atraía desde siempre. Me fascinaban las interacciones que podían brotar entre

\footnotetext{
En España, "Anacleto" se usa como insulto, y en la cultura popular de diversos países hispanohablantes hay Anacletos torpes, como el de Las Ardillitas, unas caricaturas cantantes muy conocidas en México. Sin embargo, la carga peyorativa que el nombre puede llevar es poco reconocida en este país. Es la diversión que mi interlocutor derivaba de su pseudónimo, que él mismo se puso para efectos de mi investigación, que me sugiere que él sí estaba familiarizado con este matiz.
} 
pasajeros, el intercambio de sonrisas leves, cómo un comentario o una mano tendida podía volverse apropiado donde un momento antes reinaba el silencio y la desconexión. Me fascinaban las señales escuetas entre pasajero y chofer, las breves indicaciones que daban ellos ("sin amor a la pinche puerta"), y el flujo constante, pero igualmente abreviado, de comunicación entre los choferes mismos, ya fuera en las señas que se aventaban o en las leyendas que llevaban sus camiones: "así es esto", por ejemplo, o, en lo que Jonathan Rosa (2018) llama espanglish invertido, "TAKABROWN" (está cabrón). Así fue como, un buen día al bajar del camión, me lancé hacia el checador en turno - el encargado de llevar los tiempos de la rutay le dije, sin más: "iHola! Soy antropóloga. Me gustaría saber de su trabajo”.

$* * *$

En la antropología, la ética de los encuentros etnográficos ha sido un punto de reflexión permanente. Una manera recurrente de enmarcar las relaciones en campo, y de medir sus implicaciones éticas, ha sido el intercambio: en sí, uno de los temas más sagrados de la disciplina. Se habla de devolverle algo a la comunidad, de evitar el extractivismo; se busca retribuir tanto en la escritura como de forma más inmediata ${ }^{2}$. A la vez, se reconoce que la reciprocidad suele ser frágil y compleja, algo que se logra y luego no se logra sobre la marcha y en múltiples (y no siempre concordantes) juicios y dudas retrospectivas.

Aquí, quiero mantenerme atenta a la tensión entre esos diferentes juicios e ideas de lo que constituye la reciprocidad, pero a la vez, quiero sugerir que la fragilidad del intercambio etnográfico no se desliga de lo que Jacques Derrida (1995) plantea como una imposibilidad constitutiva en el mismo concepto antropológico del don. Esta imposibilidad, quiero proponer, puede ayudar a esclarecer algunos de los abismos del intercambio etnográfico y, en particular, de este intercambio en el contexto peculiarmente capitalista del transporte público en la frontera México-Estados Unidos, al cual Anacleto me indujo.

$$
* * *
$$

El "rool" del checador es una hoja con varias tablas de celdas en blanco; a diario, se llena con una nueva secuencia de camiones, un nuevo horario meta y un nuevo horario "real". Pongo "real" entre comillas porque aquí es donde se abre el espacio de la discreción del checador, su margen

El Paper Boat Collective (2017) ofrece una discusión particularmente sensible sobre el tema, que ha servido de inspiración para este texto. 
de maniobra y control sobre los choferes, y la posibilidad de extraer de ellos una pequeña (o no tan pequeña) propina. Si el chofer llega tarde y no logra negociar con éxito, el checador lo "quema": marca su tiempo en rojo en el rool y pone en marcha la posibilidad de un "castigo" mayor. Para los choferes, quemarse es una preocupación constante, pero esta imagen de combustión y consumo improductivo tiene su contrafaz: ir lento puede ser también "comerse" el tiempo del "sayo", del que viene detrás ${ }^{3}$. El quemar y el comer dan cuenta de una forma de dividir el trabajo donde los choferes sólo en nombre son empleados, y en realidad deben pagar una cuota diaria a los concesionarios de la ruta, además de cubrir la gasolina y, con muy pocas excepciones, la renta del camión. Este arreglo preserva algunos rasgos de los orígenes comunales del negocio (que esbozaré después), aunque sólo para convertirlos en una finta que intensifica la explotación laboral. Los veinte minutos que el rool marca entre camiones aparecen como un pequeño terreno de cultivo, dentro del cual el chofer, como un tipo de ejidatario ${ }^{4}$ urbano, tiene derecho a cosechar los pasajeros que van saliendo sobre la ruta. El checador es el encargado, pues, de cuidar los límites territoriales en una distribución del tiempo como propiedad productiva $^{5}$.

\section{$* * *$}

Estos principios básicos del "sistema", como lo llaman los checadores -el rool, los castigos, el quemar y el comer-, constituyen la prestación clásica del informante para con el antropólogo. Anacleto me la entregó en una esquina desvencijada de la colonia donde vivía y donde tenía su sitio de trabajo habitual: un fraccionamiento pequeño, perdido a la vuelta de un cerro, donde terminan las construcciones y a lo lejos se alcanza a ver el mar. Aquí le sobraba tiempo, entre el periódico ir y venir de los camiones, y no le costaba dármelo a mí. A la vez, yo era un pasatiempo, y en ese sentido, le daba mi tiempo también. Así, creábamos el tiempo compartido del "cotorreo", al margen del tiempo economizado del "sistema" y rayando en los bordes del intercambio explícito (cf. Aguilar Nery, 2000, pp. 99-100; Villarreal, 2010, pp. 274 y 280).

\footnotetext{
Compárese Fleming (2016). La disciplina temporal en su caso (San Francisco, Estados Unidos) es muy diferente, pero redunda en una serie de problemas similares: la presión y el estrés para los choferes, con efectos graves sobre su salud, el antagonismo entre ellos y el público, y su mala imagen.

4 El ejido es una forma mexicana de propiedad comunal en la que cada miembro cultiva su propia parcela.

Al chofer le interesa mucho que el checador lleve honestamente el horario de su sayo de enfrente. Le interesa también (aunque menos) evitar acusaciones de parte de su sayo de atrás, y a pesar de que esto no siempre es posible, para ello depende también de la colaboración y credibilidad del checador. Aguilar Nery (2000) atestigua el papel del checador bajo el sistema colectivista, que en la ciudad de México operaba en los años 90: "El checador tiene cierta autoridad que proviene del poder delegado por todos los miembros de la agrupación" (p. 96). Es un "árbitro [...] en la contienda laboral diaria”.
} 
A la vez, el tiempo no era todo lo que le daba; yo era una pieza a su favor dentro de la economía masculina de prestigio en estos los estratos inferiores de la empresa. Como me explicó emocionado: 'Es que todos se van a estar preguntando cómo te conocí, si nomás me ven aquí metido en

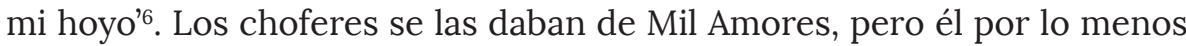
podía presumir una antropóloga. Por mi parte, aunque tuviera a veces que aclarar que no tenía una relación romántica con Anacleto, también me convenía el error, pues me aseguraba un trato más respetuoso de parte de los demás. Entre nosotros, me dio a entender - con sensibilidad y sutileza- que creía que yo era lesbiana. A ese don no le di respuesta.

\section{$\star * *$}

En su libro Dar (el) tiempo, Derrida (1995) emprende una relectura del famoso Ensayo sobre el don de Marcel Mauss (2009 [1925]). Observa que el don depende de un pequeño engaño: genera relaciones en tanto que es libre, en tanto que no se espera nada a cambio: en tanto se desprende de la consolidación de toda relación social. El intercambio, en cambio, cierra el círculo. Mauss quiere distinguir entre el don y el vil intercambio comercial, pero para Derrida, esta separación es una ficción social que se mantiene sólo gracias a la postergación en el tiempo de la contraprestación, que de todas maneras también cierra el círculo de manera interesada ${ }^{7}$. Así, el don puro aparece como un límite que motiva el intercambio pero que es imposible de lograr en la práctica: un don verdaderamente libre ni sería reconocible como tal, pues al reconocerlo, nacería la expectativa o la posibilidad de un retorno. Al margen del intercambio, en el espacio donde se traslapan lo imposible y lo imaginable, lo que el don da, dice Derrida, es el tiempo ${ }^{8}$.

Pronto, y como todos a mi alrededor, me obsesioné con el "sistema", con entender cómo realmente funcionaba todo esto. Seguía visitándole a Anacleto, pero pasaba la mayor parte de mi tiempo haciendo vueltas con los choferes o en la base, un punto de actividad intensa donde estas rutas conectan la periferia urbana con una de las garitas terrestres más transitadas del mundo. Entender la organización del movimiento implicaba

\footnotetext{
Las comillas simples indican que la cita no es textual; sólo es una aproximación.

Bourdieu (2007 [1980], pp. 157-171) también señala esta función del tiempo.

Laidlaw (2000) lúcidamente sitúa al don puro, y al argumento de Derrida en particular, en relación a los debates antropológicos sobre el don. Curiosamente, Laidlaw (y asimismo Venkatesan [2011]) se apoya en Derrida para fines bastante anti-derrideanos, es decir, para mostrar cómo el don puro establece relaciones e instituciones sociales. En mi lectura, el don puro sería más bien anti-institucional.
} 
un ejercicio nuevo para mí, y caí directo a la trampa clásica de querer una visión comprensiva. El obstáculo principal parecía ser mi incapacidad lingüística: la mayor parte de lo que me decían mis nuevos interlocutores lo percibía literalmente como un balbuceo, y cada que me topaba con una mujer, me sorprendía de lo clarito que hablaba. Nunca sabía qué tanto mi falta de comprensión era por la jerga y los albures ${ }^{9}$, por no conocer las referencias de las que se tejía el chisme, o simplemente por la pronunciación atrabancada y el ruido del camión. Me sentía como si estuviera frente a un nuevo idioma, y me apliqué. Quería convertir al lenguaje en un medio transparente para poder asir, a través de él, mi objeto de interés.

Mis dificultades, sin embargo, no eran meramente lingüísticas; eran síntoma de una diferencia sustancial con mi trabajo de campo anterior, realizado en gran medida en espacios domésticos. Era obvio que estaba en un ambiente laboral y masculino, pero no me enfrentaba al hecho de que yo era necesariamente partícipe también en su economía comunicativa (Hymes, 1974, p. 17) -la misma que primero me había atraído-y que por más que mejorara mis habilidades lingüísticas, siempre le entraría desde una posición diferenciada, como mujer. No me enfrentaba al hecho de que el "sistema" era sólo parte de un mundo social más complejo y que en este, el lenguaje y el género se entrecruzaban para jugar un papel determinante.

Mil detalles cotidianos pudieron haberme alertado ${ }^{10}$. Me resultaba imposible, por ejemplo, distinguir cuándo la agresión era agresión y cuándo era un juego, cuándo expresaba los conflictos y cuándo construía alianzas (véase Limón, 1989). 'Ellos sí, panza con panza', me dijo la única mujer chofer de la ruta, 'ipero yo no!' Nosotras estábamos exentas tanto de la violencia explícita como de las constantes fintas de bravura, los insultos y las amenazas físicas que podían en un instante concretarse o disolverse entre risas. Estos intercambios eran fundamentales para manejar las tensiones del "sistema", pero mi género era un limitante básico para aprender sus sutilezas. Pude haberme dejado reorientar en la investigación, pero no. Me empeciné. Cito de mi diario: "No sé para dónde hacerme. Necesito enfocar el trabajo de otra manera. [...] Necesito hacer preguntas específicas: sobre quemar y comer, por ejemplo. No quemas el tiempo, te quemas tú". Así, pude ignorar el drama principal que se desarrollaba ante mí.

\footnotetext{
El albur es un tipo de juego verbal; normalmente se trata de un doble sentido sexual.

10 Compárese Villarreal (2010), sobre dinámicas de género en el transporte público en Monterrey, México.
} 
Ya era 2016; ya llevaba año y medio haciendo viajecitos a Tijuana, haciendo mis vueltas con los choferes. En uno de esos retornos, me cuentan que a Anacleto lo han despedido. Ando ocupada, y hasta el siguiente viaje lo busco. Me cuesta localizarlo; más allá de la desconfianza, sus vecinos parecen realmente no saber nada. Al final resulta estar en casa de su hijo, a dos cuadras. No se encuentra, pero por la vecina me entero de que está muy enfermo.

Aquí entra una temporalidad distinta, que se mueve y se entrecruza con el tiempo capitalizado del "sistema". Contra la finitud del quemar y el comer cotidianos, repetidos día tras día en ciclos de veinte minutos, emerge, tenue pero intransigente, la infinitud del don. Frente a ella, nuestro intercambio también empieza a cambiar.

Veo a Anacleto parado como en un mini-escenario, un espacio reducido, una pequeña y abrupta curva donde apenas hay lugar para que dos camiones se arrimen a la vez. Es la parada de la garita internacional. Hay otra empresa, con múltiples rutas, con la cual pelear este espacio; los taxis amarillos, cuyos choferes son renombrados por su agresividad, tienen su sitio justo adelante; aparte, esta curva ni es paradero sino una entrada que hay que despejar cada rato. Los accidentes son constantes. Encima de todo, para los choferes es su mayor oportunidad para cargar, así que las tensiones entre ellos y los checadores están en un máximo.

En medio de todo esto una figura apachurrada, sucia, su pantalón flojo (guango, como se dice aquí), con una costura remendada y vuelta a descoser. Se le cae el pantalón, se cae él. Torea los camiones, grita, mueve los brazos. La tos le dobla el cuerpo al piso. Arrastra una pierna grotescamente hinchada; el pantalón rajado revela la piel tersa, delgada, manchada de rojo vivo; el pie, como un enorme tamal, lo tiene embutido en una chancla. Me sonríe: va mucho mejor. Había pensado, "Hasta aquí llegué", pero no: "Hierba mala nunca muere". 
Dar (el) tiempo tiene un libro compañero, Dar la muerte (2006). En él, Derrida vuelve sobre la unicidad de la muerte propia, la imposibilidad de compartirla, como el núcleo del cual nace -en la tradición europeala responsabilidad. Se ve en el suicidio de Sócrates, por ejemplo. En la "vigilia de la muerte posible" (p. 25), uno se enfrenta a ella, se encarga de ella y, así, termina dándosela uno mismo. Es un ejercicio solitario, tomar la responsabilidad de esto que al fondo es lo único realmente propio, que le atañe a uno y a nadie más. Y hacerlo es un acto soberano. Da libertad por encima de la muerte: da un tipo de inmortalidad. Como don, podríamos decir, lo que da la muerte es este otro tiempo.

En la vigilia de su muerte posible, Anacleto vacila entre la finitud ("hasta aquí llegué") y algo que en términos literales no es supervivencia sino inmortalidad: "hierba mala nunca muere". Es una sugerencia provisional, envuelta en una broma, una negación momentánea de la muerte y un pequeño gesto que la posterga. Pero a la vez, oblicua y solitariamente, Anacleto se encarga.

\section{$* * *$}

Antes, cuando Anacleto era un nombre y no una burla, tenía su significado. Venía del griego, y quería decir "invocado" o "solicitado". Así como Abraham fue solicitado por Dios. Es en la historia de Abraham que Derrida se concentra para probar el límite del concepto de responsabilidad, el punto en el que se vuelve, como el don, puro e imposible, apenas imaginable. La responsabilidad que compela a Abraham es "injustificable, secreta y absoluta" (p. 73); si no lo fuera, no existiría como tal, tan cercana a la locura es. El compromiso es entre él y Dios: una muerte que le daría a su hijo para dársela a Dios. Un sacrificio sin sentido más allá del compromiso mismo; más allá, dice Derrida, del llamado de Dios y el "heme aquí" de Abraham (p. 136 y 148). Así es como la responsabilidad absoluta se contrapone al orden de la ética, a la responsabilidad que Abraham tiene para con su hijo, en su amor por él, así como a la que tiene con todos los demás a su alrededor. Cuando Abraham lleva a Isaac al monte, entonces, no se lo dice a nadie.

Al fondo de la burla y el desprecio, Anacleto invoca esta historia, la historia de la responsabilidad europea. Una historia entreverada con muerte, y atisbos de soberanía. 
Me ignora. Está trabajando. Me siento sobre la barrera de cemento

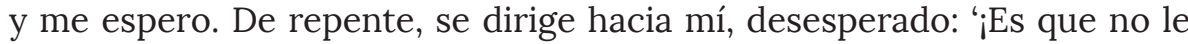
puedo atender como antes!' Es la primera vez que me habla de usted. Dice que es por la tos, que no puede hablar, pero queda claro: ya no tiene tiempo para mí. Me voy.

Otro día. Encuentro a Anacleto tirado en una silla plegable, de esas que la gente lleva a la playa o a acampar. Respinga. Dice que los jefes no le han querido dar de alta en el sistema de salud pública, por eso tiene que trabajar. Su ex lo podría meter, pero no quiere que después ella ande diciendo que le ayudó. Está pagando los estudios con un médico privado; cuando los tenga, le darán de alta en el seguro y se podrá internar.

Me emputo y le digo que yo le presto el dinero. Llega un camión, y se va a atenderlo. Cuando vuelve, dice que lo pensará.

\section{$\star * *$}

En la ruta, dicen, el tiempo es oro. Mi error es pensar que puedo invertir esta equivalencia: que le puedo comprar más tiempo. O más bien, mi error es mezclar los tiempos, pensar que el tiempo que vale sea uno que se pueda comprar. Y, además, que yo sea quien para hacer eso ${ }^{11}$.

Cuando Abraham lleva a Isaac al monte, no le dice nada, ni tampoco le dice nada a Sara. La tradición europea de la responsabilidad, observa Derrida, ha sido muy exclusivamente masculina. Al no decirle nada a Sara, Abraham guarda su compromiso con Dios. Su compromiso lo obliga a sustraerse de esa relación (su matrimonio), a transgredirla; lo obliga al secreto. ¿Qué le pasaría a la "lógica de la responsabilidad sacrificial" si interviniera en ella una mujer? "¿Es en lo más profundo de sí", pregunta Derrida, "una exclusión o un sacrificio de la mujer?" (p. 88).

\footnotetext{
Sin duda, "el tiempo es oro" colma la reificación del tiempo que el "sistema" efectúa. Remite a la frase "time is money" (el tiempo es dinero), que Benjamin Franklin hizo famosa y que Weber cita para dilucidar La ética protestante y el espíritu del capitalismo (2003 [1905]). Sin embargo y como sugiere la dinámica de "quemar" y “comer", la valoración del tiempo en la ruta si bien es calculativa, es muy distinta de la valoración industrial del tiempo (véase Thompson, 1984 [1967]). Volveré sobre este punto al final del ensayo.
} 
Son preguntas que lanza y -cosa excepcional en su texto- deja sin ningún intento de contestarlas.

Ni yo ni la ex podemos pagar, podemos "ayudar", en esta situación. Estropearíamos todo. Anacleto se comporta como si lo más valioso estuviera en juego, y arriesga su vida por ello. Yo no veo ese valor. No veo que se sacrifique por nada. Pero detrás o tal vez dentro de cualquier cuestión de orgullo masculino, de todos los beneficios que puede conllevar (visto, sobre todo, en un nivel colectivo), está el vacío de un sacrificio sin retorno. Es el mismo vacío que está al fondo de la soberanía, de su arrojo y valentía, de su voluntad indiferente al peligro y a la muerte. El sacrificio que busca un retorno no es ningún sacrificio; se subordina al cálculo. No es soberano. El don de la muerte, al contrario, es "un don sin economía" (p. 108). Si fuera por algo, libre no sería ${ }^{12}$.

El sábado, me cuenta, fue al doctor. Tuvo que lavar los baños para irse. Pensó en llamarme. Decírmelo es como un pequeño gesto de consideración; a la vez, constata su decisión de no hacerlo. Cuando le pregunto qué le dijo el doctor, sonríe de nuevo: "Hierba mala nunca muere". Pero al rato añade: "Ya ando en las últimas"13.

No está entre mis apuntes, pero esto ha de haber sido cuando Anacleto aceptó mi oferta de dinero. Fue una conversación tensa: volví a insistir cuando me mostró una receta para una medicina que no podía pagar. Cuando finalmente dijo que sí, sin embargo, tuve la sensación de que él sentía que había logrado engañarme. Pidió \$500 pesos, pero como tanteando mi reacción, a ver si no se me hacía mucho ${ }^{14}$. Me enojé más. Si me había parecido absurdo morir simplemente para evitar la humillación a manos de una mujer, más absurdo aún me pareció inventarse que

\footnotetext{
Así como los dos libros de Derrida, El sacrificio (Hubert y Mauss, 2010 [1898]) complementa al Ensayo sobre el don; invita una lectura paralela, como la de Derrida, pues tiene al centro el mismo impulso paradójico hacia el desinterés.

13 Aquí invierte la trayectoria de peor a mejor que primero trazó con el contraste entre "hasta aquí llegué" y "hierba mala nunca muere". En cada caso, es un movimiento entre un tiempo finito y otro infinito. "Las últimas" emerge contra el fondo del "nunca muere". "Nunca muere" aparece como un lema, una clave o contraseña, que se repite con la finalidad de colocarse en un tiempo que, pase lo que pase, seguirá siendo infinito. Con la frase, Anacleto pasa continuamente el umbral de ese tiempo. Más que posponer la finalidad (la muerte), la interrumpe.

14 Este detalle, entre otros, sugiere que mi condición de clase no siempre era muy evidente para mis interlocutores. Mencionaban con envidia el hecho de que viajaba, pero también sabían que me quedaba en la misma colonia donde varios de ellos vivían.
} 
me estaba timando, y por una cantidad tan pequeña, cuando era evidente que realmente se estaba muriendo.

Poco después, supe que había andado presumiendo el billete. Pero a él no lo volví a ver ${ }^{15}$.

El don de la muerte como don puro que da la responsabilidad no existe en ningún lado. Es una sugerencia que emerge por ratos, sutilmente, bajo condiciones sociales particulares y siempre en tensión con ellas, siempre en tensión con las responsabilidades corrientes, o lo que Derrida (2006) llama "la generalidad de la ética" (p. 73). Pero se deja sentir. Cuando la muerte entra en escena, el intercambio se mueve. Mi reacción es meter al dinero también, hacer explícita la desigualdad. Trato de contrarrestar una desigualdad (él se va a morir, yo no) con otra (la económica), pero termino sumándolas. Anacleto voltea la balanza: el dinero no es prestación ni contraprestación de mi parte, sino un robo suyo. Toma sin dar. Restaura la dirección debida del flujo entre hombre y mujer; lo restaura a su favor, pero siempre a riesgo de su propia vida. A la vez, donde yo hubiera convertido su don original hacia mí en una deuda y, así, en un intercambio interesado, con su estafa él lo deja como don libre, al margen del reconocimiento y al margen de cualquier posibilidad de retribución.

Van tres semanas que no sé de Anacleto. Me sumerjo en el trabajo; en mis libretas no hay especulaciones. Un día, el 64 -los choferes se conocen por el número de su camión- me hace señas. Con urgencia, él y su esposa me dan indicaciones: en la Clínica 20, tercer piso, cama 311. Se los dijo Alfredo. Ve, me dicen.

Dentro de dos horas debo de salir de la ciudad; no tengo tiempo. Busco, entonces, a Alfredo, pero lo hago con cautela, pues siempre he intentado minimizar en lo posible mi relación con Anacleto ante él. Alfredo es uno de los checadores principales, que coordinan a los demás.

\footnotetext{
No sorprenderá que mi punto de vista era únicamente mío. Ya había recibido varias advertencias: "Aquí hay muchos que van a tratar de aprovecharse de ti, primero entre ellos Anacleto". Vaya intercambio etnográfico; vaya retribución de $\$ 500$ pesos cuando para todos ahí no era una mínima contraprestación de agradecimiento sino una estafa. A la vez, cada advertencia no podía más que parecerme otro don: un gesto de cuidado que sólo aumentaba mi gratitud. Con ellas, los choferes retomaban los estereotipos negativos sobre el medio para proyectarlos sobre sus compañeros y posicionarse a sí mismos como hombres dignos y decentes, de familia.
} 
Anacleto me ha dicho que es "buena onda" (de carácter llevadero), que no es "cortante" como otros, y conmigo ha sido, de hecho, prudentemente generoso. Pero pasa la mayor parte de su tiempo con los de arriba, los administradores y socios que vienen a echarle un ojo al negocio, y en especial con el representante del "sindicato", que los choferes aseguran está ahí para aplastar cualquier intento de movilización y que sin duda tuvo que ver con la negociación en torno al seguro de Anacleto ${ }^{16}$. Son hombres altos, corpulentos, y Alfredo se defiende entre ellos en su propia esfera de competencia y cotorreo masculino.

Le pregunto simplemente, entonces, si no sabe nada de Anacleto. Jamás hubiera podido anticipar su respuesta. En un tono jocoso, cantadito, me contesta: "¡Yo creo que ya se murió!" "Bien puede ser", le contesto, atónita. ¿La satisfacción es real? ¿Es ironía? ¿Coraje conmigo? ¿Con los jefes? "Lo incineraron", me dice entonces y, con la misma actitud socarrona, antes de darme la espalda: “¿No sabías?"

$$
* * *
$$

Lo incineraron: lo quemaron. Llegó tarde, se le acabó el tiempo, se quemó. No tengo cómo interpretar el muro que Alfredo avienta entre mí y Anacleto, pero esta es la versión que se establece entre los choferes. A veces me preguntan, con cuidado y sensibilidad, si acaso yo sé algo. Nadie tiene detalles, pero lo indudable es que Anacleto ya no está.

Un año después, Everardo me invita a acompañarlo en una vuelta. Es un hombre parco, y siempre he supuesto que le caigo mal. Ahora, para mi sorpresa, aprovecha para echarse una "terapiada": habla de sus problemas con su mujer, la decepción que ella siente del matrimonio, su propio deseo recurrente de suicidarse. Es un tipo de conversación extendida que era habitual en mi trabajo de campo anterior, pero que en esta investigación ha sido una rareza; se debe, claro, a que a esa hora de la tarde casi no hay pasajes, pero se debe también a la economía comunicativa -o la anti-economía comunicativa- que rige sobre la ruta.

De regreso, me cuenta una historia. Es una historia que tiene en esta situación un valor metapragmático: es un comentario sobre nuestra propia interacción, que me amonesta a respetarla y me enseña cómo.

\footnotetext{
Robledo y Cano (2020) dan cuenta de la lucha de un conductor de camiones en Guadalajara quien fue despedido por intentar organizar a sus compañeros. Las resonancias con el contexto tijuanense son muchas.
} 
Una vez, uno de los checadores lo descubrió llorando en su camión. Sintió vergüenza. Pero el otro nada más le dijo: “Tás' agüitado [triste], ¿verdad? ¿Tienes problemas en casa?" Nunca volvió a mencionar el asunto. Es un silencio que Everardo admira y agradece profundamente, que lo sigue sintiendo como un bálsamo, pero que se esfumaría con cualquier gesto de reconocimiento. Momentos después, me dio un don de vuelta. Me preguntó, sin ponerle ningún énfasis, si sabía que Anacleto estaba de regreso ${ }^{17}$.

Un fulano, dice la Real Academia, es una "persona indeterminada o imaginaria". Recibir de y dar a tal figura -un Anacleto- coloca el intercambio al borde de ese abismo que es el don puro: don irreconocible de una persona de existencia ambigua, que finalmente desaparece. El nombre falso que mi "informante" escogió resulta demasiadamente auténtico; remarca esa cualidad ficcional e imposible del don que terminó desbordando nuestra relación. El intercambio no se sostiene; yo lo quiero reconocer, y eso estropea todo. Pero en realidad los intercambios entre estos hombres - los que valen para ellos- son todos así: al borde del precipicio, frágiles, que entre los forcejeos y los albures requieren de una delicadeza inmensa. No son tan diferentes de los intercambios entre pasajeros que primero me atrajeron a este ámbito: pequeños dones entre desconocidos (fulanos) que no cimientan una relación, sino que se dispersan en lo público ${ }^{18}$. Frente al "sistema", frente a la forma en que reifica al tiempo y lo acapara para la empresa (una jornada en este medio, no hay que olvidar, puede durar hasta 15 o 16 horas), los dones son esquivos y, por eso mismo, preciosos. Requieren de responsabilidad para guardar el compromiso secreto, escurridizo, absoluto e injustificable, que está no en el llamado de algún Dios lejano, sino en el llamado íntimo, cercano, de todos los otros que nos rodean ${ }^{19}$.

17 La idea de una economía comunicativa (Hymes 1974, p. 17) implica una visión no de los intercambios lingüísticos individuales como sistema, sino de los tipos de eventos comunicativos como un todo coherente que organiza una sociedad. De todos modos, sin embargo, estriba en las metáforas economicistas que, empezando tal vez con la frase "intercambio de palabras", han dejado una impronta tan profunda en las formas occidentales de entender el lenguaje. Piénsese, por ejemplo, en cómo Ferdinand de Saussure se refería a la lengua como un "tesoro" (1983 [1916], p. 78). Los choferes parecen valerse de una ideología lingüística (Schieffelin, Woolard y Kroskrity, 2012 [1998]) contrastante, aunque relacionada, al enmarcar implícitamente algunas de sus comunicaciones como dones.

18 Villarreal (2010) explora de manera iluminadora las alianzas de clase entre pasajeros y choferes que se expresan mediante "dones no rastreables" (p. 273), por ejemplo, cuando un pasajero devuelve su boleto al chofer para que lo revenda y se quede con dinero que de otra manera entregaría a la empresa (véase también la p. 280)

19 Cuando Derrida intenta romper con la tradición europea de la responsabilidad, lo hace con esta propuesta: tout autre est tout autre, todo otro es completamente otro. La otredad absoluta, y la responsabilidad absoluta, no están en esa ausencia suprema que se llama Dios. Están en todas nuestras relaciones, llamándonos (2006, p. 90). 
Al momento de mi trabajo de campo, el "sistema" de la entidad concesionaria de la ruta todavía derivaba del viejo modelo Hombre-Camión, que surgió en los años posrevolucionarios (Davis, 1999). Originalmente, las concesionarias eran sociedades de choferes, cada uno dueño de su propio camión: de ahí el nombre del modelo. La propuesta en su momento fue reaccionaria, ideada para quebrar la organización sindical entre los tranviarios de la ciudad de México. Pero resultó en una forma social no disimilar al ejido, que recibe la dotación como colectividad y luego distribuye los derechos de usufructo entre los miembros. El quemar y el comer, que tanto preocupaban a choferes y checadores, eran restos de este pasado colectivista.

En el caso que conocí, este modelo parece haber sobrevivido más o menos intacto hasta una fecha relativamente tardía: en 1971, los miembros de la asociación eran los choferes mismos, y es hasta 1992 que netamente pierden el control sobre ella ${ }^{20}$. Los choferes que conocí se asemejaban más a aparceros que a ejidatarios, pero los restos de independencia que defendían se debían a las secuelas del Hombre-Camión. Hoy, los socios han logrado el cambio al "modelo empresarial", y los choferes y checadores que conocí se han dispersado a buscar trabajo donde puedan. Para los socios, ellos como individuos estaban viciados por el viejo modelo y prácticamente ninguno tenía el potencial para "modernizarse". Detrás del drama de la muerte de Anacleto - como el quemarse absoluto del hombre-residuo, del hombre-desecho comido por el capitalismo voraz ${ }^{21}$ de la frontera-, estaba esta otra finitud del Hombre-Camión como residuo de la Revolución, elemento no-sincrónico (Bloch, 1977) en una ciudad fronteriza que se concibe como nodo de flujos globalizados. También al Hombre-Camión lo incineraron, su tiempo se lo comió la empresa ${ }^{22}$.

Entre los fragmentos destrozados de una modernidad caduca, los intercambios entre trabajadores constituían no una economía, sino una frágil ecología, una efímera solidaridad siempre a punto de desvanecerse entre los conflictos estructuralmente fomentados y la represión laboral directa.

20 Aunque todos se referían a "la empresa", seguía siendo formalmente una sociedad. En 1971, cuando se reconstituyó legalmente, hubo unos 80 socios que firmaron con la profesión de "chofer". Todos pertenecían al Sindicato de Trabajadores del Volante, Similares y Conexos. En 1992, se volvió a reconstituir con unos 40 socios. Ni uno de ellos era chofer. Cuando realicé mi trabajo de campo, los socios eran en general dueños de placas (matrículas), quienes las rentaban a dueños de camiones, quienes rentaban sus camiones a los choferes (a pesar de que técnicamente los choferes eran empleados de la sociedad). Todavía existían unos cuantos choferes que eran dueños de su propio camión, pero ni dueños ni choferes tenían representación ante la asociación. La trayectoria histórica entre el Hombre-Camión y otros modelos varía entre ciudades; para un ejemplo contrastante, véase Villarreal y Mercier (2010).

21 Le debo a Alejandra Leal el haberme recordado esta frase tan apta.

22 A la vez, el capitalismo voraz de la frontera depende de la resurrección de los residuos. No es inimaginable que al Hombre-Camión lo resuciten, como a Anacleto, para después volverlo a quemar. 
En la antropología, la discusión en torno de la relación entre don y mercancía es larguísima, pero en este caso, son los mismos trabajadores que los oponen al retomar la ideología del don puro y llevarla a una expresión extrema, como contraste absoluto con y escape de la ultra-mercantilización del tiempo, la apropiación por la empresa de prácticamente todas sus horas de vigiliaa ${ }^{23}$. Aquí, el tiempo está de nuevo al centro de la oposición entre don y mercancía. La expropiación del tiempo por el patrón es tan radical que orilla el intercambio no mercantilizado a tomar formas igualmente radicales: por un lado, la extraña infinitud del sacrificio mortal como el don más puro y, por otro, los delicados dones comunicativos que los trabajadores se ofrecen entre ellos. Su misma práctica los enmarca como diminutos acercamientos al don puro, que atestiguan la persistencia de la solidaridad a pesar de todos los obstáculos en su contra.

En la frontera, la herencia revolucionaria sobrevive como un resto que la voracidad capitalista pervierte. Profundiza el abismo del don y hace que punce no sólo la posibilidad del intercambio etnográfico, sino de los intercambios que sostendrían cualquier solidaridad laboral. Aquí, los verdaderos dones no regresan. La responsabilidad que imponía la muerte de manera más urgente que nunca era hacia ese frágil intercambio que da otro tiempo y que le hace frente a toda finitud. Al quererlo reconocer, no reconocí nada, y el intercambio, así como Anacleto, se desvaneció ${ }^{24}$.

$* * *$

Al ver a Anacleto ahí instalado frente a la paletería donde primero lo había conocido, volví a sentir un poco del coraje del año anterior. Entonces, cuando me saludó como de costumbre y me preguntó cómo había estado (él se veía muy restaurado), le contesté: "Bien. No morí ni reviví ni nada". "Yo sí", me dijo, como si no fuera precisamente por eso que se lo había dicho. Describió cómo se había desmayado ahí en la base entre los camiones y la gente, cómo fue su familia por él y se lo llevaron. Ahora come pura verdura cocida sin sal, pero aquí anda.

23 Es Parry (1986) quien sugirió en un artículo influyente que el don puro debería de considerarse como una ideología, que emerge históricamente precisamente en contraste con la mercancía.

24 Hay otra lectura posible de los hechos, que corre en contra de la que he hecho aquí, sin cancelarla. Desconozco si la empresa finalmente inscribió a Anacleto en el sistema de salud pública, posibilitando la atención médica que salvó su vida. En ese caso, su vida sería un don del patrón que amarraría una relación de intercambio clientelar. La enfermedad de Anacleto irrumpió como complicación a su despido, pero su recontratación posterior le dio continuidad al intercambio. Como el secreto de Abraham con Dios, la dádiva del patrón también fue uno que todos guardaron. Guardaron asimismo hasta qué punto pudo haber sido una respuesta al espectáculo de autosacrificio que Anacleto ofreció. 
Todo esto me lo contó, pero con cierta sutil distancia e incomodidad.

En este punto, llegó una joven, bonita, maquillada, con un arete en la nariz o tal vez en la ceja. Se recargó sobre el congelador, recogió el rool de Anacleto (un gesto fuerte de intimidad y confianza), y se puso a leer el chisme que estaba ahí plasmado. ‘¿Poncho no ha bajado?!' exclamó, fingiendo escandalizarse, demostrando su familiaridad con las cifras arcanas: el mundo social, las angustias y tensiones que exponen a la vista de quien conoce sus claves. ‘A mí me tiene que mantener!' bromeó. Sentí que estaba haciendo alarde de su habilidad por interrumpirnos y absorber la atención de Anacleto; pacientemente me esperé, hasta que por fin pude cruzar la mirada con ella y obtener, para mi alivio, una sonrisa. Si era de triunfo o de simpatía ya poco me importaba. Tomé la oportunidad de extraerme, y Anacleto y yo nos despedimos.

Los intercambios se desvanecen, pero el don es una hierba, que nunca muere. Lo devuelvo como puedo, a nadie -a ustedes-, aquí.

\section{Agradecimientos}

Agradezco a Paul Liffman por el primer empujón; recibí otros más de Alejandra Leal, Nitzan Shoshan, y Mario Rufer. Presenté versiones en el coloquio "Estudios culturales y objetos ilegítimos" en la Universidad Autónoma Metropolitana, Unidad Xochimilco; en el seminario "Reordenamiento y regulación del transporte público concesionado en la Ciudad de México" en la Universidad Nacional Autónoma de México; y en dos mesas del congreso anual de la American Anthropological Association (gracias a Danilyn Rutherford y a Caroline Melly por sus comentarios). Por su lectura cuidadosa, agradezco a Alejandra Leal, Rodrigo Parrini, Paco Cruces y los dictaminadores de Virajes. A Vladimir Caraballo y Daniel Ramírez, gracias por darme la oportunidad de participar aquí. Finalmente, y de corazón, muchas gracias a todos los que me recibieron en la ruta.

\section{Referencias bibliográficas}

Aguilar Nery, J. (2000). Las culturas del volante en la ciudad de México. Aproximación etnográfica a los choferes del transporte público. Estudios sobre las Culturas Contemporáneas, 6(12), 85-110.

Bloch, E. (1977 [1935]). Nonsynchronism and the Obligation to Its Dialectics. New German Critique, 11, 22-38. 
Bourdieu, P. (2007 [1980]). El sentido práctico (Trad. A. Dilon). Buenos Aires: Siglo XXI.

Davis, D. (1999). El Leviatán urbano. La ciudad de México en el siglo XX. México: Fondo de Cultura Económica.

Derrida, J. (1995). Dar (el) tiempo. I. La moneda falsa. Barcelona: Paidós.

Derrida, J. (2006). Dar la muerte. Barcelona: Paidós.

Fleming, M. (2016). Mass Transit Workers and Neoliberal Time Discipline in San Francisco. American Anthropologist, 118(4), 784-795.

Hubert, H. y Mauss, M. (2010 [1898]). El sacrificio. Magia, mito y razón. Buenos Aires: Cuarenta Ríos.

Hymes, D. (1974). Foundations in sociolinguistics: An ethnographic approach. Philadelphia: University of Pennsylvania Press.

Laidlaw, J. (2000). A free gift makes no friends. Journal of the Royal Anthropological Institute, 6(4), 617-634.

Limón, J. (1989). Carne, carnales, and the carnivalesque: Bakhtinian batos, disorder, and narrative discourses. American Ethnologist, 16(3), 471-486.

Mauss, M. (2009 [1925]). Ensayo sobre el don: forma y función del intercambio en las sociedades arcaicas. Buenos Aires: Katz.

Paper Boat Collective. (2017). Introduction: Archipelagos, a Voyage in Writing. En A. Pandian y S. McLean (eds.), Crumpled Paper Boat: Experiments in Ethnographic Writing (pp. 11-28). Durham: Duke University Press.

Parry, J. (1986). The Gift, the Indian Gift and the 'Indian Gift'. Man, 21(3), 453-473.

Robledo, H. y L. Cano. (2020). De El Hombre-Camión al Frente Común de Usuarios y Operadores. Memoria de una investigación con metodología audiovisual colaborativa. Encartes 3(5), 56-78.

Rosa, J. (2018). Looking Like a Language, Sounding Like a Race: Raciolinguistic Ideologies and the Learning of Latinidad. Oxford: Oxford University Press.

Saussure, F. (1983 [1916]). Curso de lingüística general (Trad. A. Alonso). Madrid: Alianza.

Schieffelin, B., Woolard, K. y Kroskrity, P. (Coords). (2012 [1998]). Ideologías lingüísticas. Práctica y teoría. Barcelona: Catarata.

Thompson, E.P. (1984 [1967]). Tiempo, disciplina de trabajo y capitalismo industrial. En Tradición, revuelta y consciencia de clase. Estudios sobre la crisis de la sociedad preindustrial. Barcelona: Crítica.

Venkatesan, S. (2011). The social life of a "free" gift. American Ethnologist, 38(1), 47-57.

Villarreal, A. (2010). The Bus Owner, the Bus Driver, and His Lover: Gendered Class Struggle in the Service Work Triangle. Work and Occupations 37(3), 272-294.

Villarreal, A. y D. Mercier. (2010). ¿Hacia un sistema integrado de transporte urbano en el área metropolitana de Monterrey?: La figura del hombre camión. En L. Palacios (ed.), Cuando México enfrenta la globalización. Permanencias y cambios en el área metropolitana de Monterrey (pp. 457-468), Monterrey: Universidad Autónoma de Nuevo León.

Weber, M. (2003 [1905]). La ética protestante y el espíritu del capitalismo. México: Fondo de Cultura Económica. 